\title{
Comparison of the six-minute walk test with a cycle-based cardiopulmonary exercise test in people following curative intent treatment for non-small cell lung cancer
}

Vinicius Cavalheri, PhD; $;^{1,2}$ Sue Jenkins, PhD; ${ }^{1,2,3}$ Nola Cecins, MSc; ${ }^{2,3,4}$ Kevin Gain, PhD; ${ }^{5,6}$ Kylie Hill, $\mathrm{PhD}^{1,2,7}$

${ }^{1}$ School of Physiotherapy and Exercise Science, Faculty of Health Sciences, Curtin University, GPO Box U1987, Perth, WA, 6845, Australia

${ }^{2}$ Institute for Respiratory Health, Sir Charles Gairdner Hospital, Nedlands, WA, 6009, Australia

${ }^{3}$ Physiotherapy Department, Sir Charles Gairdner Hospital, Hospital Avenue, Nedlands, WA, 6009, Australia

${ }^{4}$ Community Physiotherapy Services, 151 Wellington Street, Perth, WA, 6000, Australia

${ }^{5}$ Department of Respiratory Medicine, Royal Perth Hospital, GPO Box X2213, Perth, WA, 6001, Australia

${ }^{6}$ School of Medicine and Pharmacology, University of Western Australia, GPO Box X2213 Perth, WA, 6847, Australia 
${ }^{7}$ Physiotherapy Department, Royal Perth Hospital, GPO Box X2213, Perth, WA, 6001, Australia

\section{Corresponding author:}

A/Prof. Kylie Hill

School of Physiotherapy and Exercise Science, Faculty of Health Sciences, Curtin

University

GPO Box U1987, Perth, Western Australia, 6845

Phone number: +61(8) 92662774

Email address: $\underline{\text { K.Hill@curtin.edu.au }}$ 


\section{Abstract}

This study in people following curative intent treatment for non-small cell lung cancer (NSCLC) aimed to; (i) compare both the magnitude of impairment in exercise capacity and exercise responses measured during the six-minute walk test (6MWT) and the cardiopulmonary exercise test (CPET), and (ii) investigate the effect of test repetition on

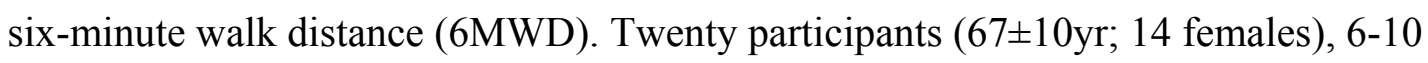
weeks following lobectomy, underwent a CPET and two 6MWTs. Peak exercise responses, dyspnoea and leg fatigue as well as heart rate (HR) and oxygen saturation $\left(\mathrm{SpO}_{2}\right)$ during the 6MWT were compared to those during the CPET. Compared with exercise capacity expressed as peak rate of oxygen consumption $\left(\mathrm{VO}_{2 \text { peak }}\right)(\%$ pred $)$ measured during the CPET, exercise capacity was less impaired when expressed as $6 \mathrm{MWD}$ (\%pred) ( $81 \pm 10$ versus $63 \pm 15 \%$ pred; $p<0.001)$. Compared with the CPET, the 6MWT elicited lower peak HR ( $119 \pm 15$ versus $128 \pm 18 \mathrm{bpm} ; p=0.02)$, lower $\mathrm{SpO}_{2}(93 \pm 2$ versus $95 \pm 3 \%$; $p<0.05)$, less dyspnoea $(3.1 \pm 1.6$ versus $6.9 \pm 2.6 ; p<0.01)$ and less leg fatigue $(2.0 \pm 1.9$ versus $6.8 \pm 2.4 ; p<0.01)$. The $6 \mathrm{MWD}$ increased $19 \pm 19 \mathrm{~m}(4 \pm 4 \%)$ with test repetition $(p<0.001)$. In people following curative intent treatment for NSCLC, the 6MWT appears to elicit sub-maximal exercise responses when compared with the CPET. There is a significant effect of test repetition on 6MWD.

Keywords: exercise test; carcinoma, non-small cell; exercise tolerance 


\section{Introduction}

Lung cancer is the most common cause of death from malignancy in males and females. ${ }^{1}$ For people diagnosed with early stage non-small cell lung cancer (NSCLC) (i.e. stages I-IIIA), surgical resection of the tumour (with or without adjuvant chemotherapy) offers a chance of cure. ${ }^{2}$ Although the overall 5-year survival rate for people with lung cancer is approximately $15 \%,{ }^{1,3}$ for those with early stage NSCLC who complete curative intent treatment, the 5 -year survival rate can be as high as $80 \%{ }^{2}$ Therefore, in people following curative intent treatment for early stage NSCLC interest is increasing in the impact such treatment has on functional status, as well as the role rehabilitative strategies, such as exercise training, may have in optimising recovery. Specifically, earlier work has demonstrated that people who have completed curative intent treatment for NSCLC have substantial impairments in exercise capacity. ${ }^{4-10}$ Compared to pre-operative values, the peak rate of oxygen uptake $\left(\mathrm{VO}_{2 \text { peak }}\right)$ following lung resection is reduced by 10 to $28 \%{ }^{8-10}$ Further, there have been some randomised controlled trials, and a recent Cochrane review, that have investigated whether this impairment in exercise capacity can be ameliorated with exercise training. ${ }^{11-13}$

Although there is interest in exercise capacity and the role of exercise training in this population, data exploring the responses to exercise in people following curative intent 
treatment for NSCLC are scarce. The cardiopulmonary exercise test (CPET) is a laboratory-based assessment which provides a global assessment of an individuals' response to exercise. ${ }^{14}$ Even though several protocols exist, those which impose a progressive increase in work rate are most common. The CPET is accepted as the gold standard method to quantify exercise capacity and the results can be used to prescribe the initial intensity for exercise training. ${ }^{14}$ It is however, expensive to perform and requires access to specialised equipment and personnel. Therefore, the six-minute walk test (6MWT), in which an individual to asked to walk as far as possible in six minutes, is commonly used in pulmonary rehabilitation programmes to quantify exercise capacity and prescribe the initial intensity for walking-based exercise training. ${ }^{15-17}$

Studies in people with moderate-to-severe chronic obstructive pulmonary disease (COPD) that have compared exercise responses during the 6MWT to those during the $\mathrm{CPET}^{18-23}$ have shown no difference in $\mathrm{VO}_{2 \text { peak }}{ }^{18,19,21}$ and either minimal ${ }^{22}$ or no difference ${ }^{18-21,23}$ in peak heart rate (HR) between the two tests. In people with COPD, although the 6MWT has been shown to elicit similar peak responses as the CPET, walking-based exercise training is often prescribed and tolerated at a high percentage (e.g. $80 \%$ ) of the average speed achieved during the $6 \mathrm{MWT} .{ }^{24,25}$ In people following curative intent treatment for NSCLC, no studies have compared the exercise responses measured during the CPET and the 6MWT. Hence, it is unknown whether the 6MWT 
elicits peak or sub-maximal exercise responses, relative to the CPET. Such information will assist clinicians to decide whether it is appropriate to prescribe walking-based exercise training at $80 \%$ of the average speed achieved during the $6 \mathrm{MWT}$, or whether a higher initial intensity may be tolerated in this population.

The European Respiratory Society/American Thoracic Society (ERS/ATS) technical standard on field walking tests ${ }^{26}$ recommends that the $6 \mathrm{MWT}$ should be performed twice to account for any effect test repetition may have on six-minute walk distance (6MWD). However, this recommendation is based largely on studies that recruited people with COPD. ${ }^{26,27}$ No studies have explored the effect of test repetition on 6MWD in people following curative intent treatment for NSCLC.

Therefore, in people following curative intent treatment for NSCLC, the aims of this study were to; (i) compare the magnitude of impairment in exercise capacity and exercise responses measured during the 6MWT and CPET, and (ii) investigate the effect of test repetition on 6MWD. As we collected several cardiorespiratory variables during the CPET, we also speculated on the mechanisms of exercise limitation in this population. 


\section{Methods}

\section{Study design and participants}

This was a cross-sectional and observational study. Data collection was performed between February 2012 and April 2014. People were included if they were 6 to 10 weeks following lobectomy for NSCLC (stage I-IIIA) or, for those who required adjuvant chemotherapy following surgery, 4 to 8 weeks following their last treatment. Exclusion criteria comprised; presence of co-morbid conditions that may compromise safety during the assessments, severe neuromusculoskeletal limitations or the inability to understand spoken or written English. All participants gave written informed consent. The study was approved by the Ethics Committees of two tertiary hospitals (approval numbers 2011/105 and RA-11/033) and Curtin University (HR-178/2011).

\section{Protocol}

Measures were collected over 2 assessment days, separated by at least 7 days. On the first day age, height and weight were recorded, functional limitation resulting from dyspnoea was assessed by the modified Medical Research Council dyspnoea scale (MMRC), ${ }^{28,29}$ and participants underwent two 6MWTs. On the second day, measures were made of forced expiratory volume in 1 second $\left(\mathrm{FEV}_{1}\right)$, forced vital capacity (FVC) and single breath diffusing capacity for carbon monoxide (The Elite-Series-DX- 
plethysmograph, Medical Graphics Corporation, USA) $)^{30-34}$ and participants completed a CPET.

\section{Exercise capacity measures}

\section{Cardiopulmonary exercise test}

A symptom-limited ramp cycle ergometry exercise test was performed on an electronically braked bicycle ergometer (ER-900 Jaeger, Viasys-Healthcare-GmbH, Germany) in accordance with published guidelines. ${ }^{14}$ The magnitude of work rate increments was individualised using a published equation, ${ }^{35}$ with the goal of achieving a test duration of 10 minutes. ${ }^{14,35,36}$ Increments varied from 1 watt (W) every 12 seconds to $1 \mathrm{~W}$ every 5 seconds. Participants rested on the bike for 3 minutes, then completed unloaded cycling (between 50-60rpm) for 3 minutes, after which time the resistance on the bike progressively increased until symptom limitation. Breath-by-breath measurements were collected (Medgraphics-CardiO2; Medical Graphics Corporation, USA). Blood pressure was measured every 2 minutes by automated sphygmomanometry, HR was measured via twelve-lead electrocardiography and peripheral capillary oxygen saturation $\left(\mathrm{SpO}_{2}\right)$ was continuously monitored via pulse oximetry (Rad4; Masimo Corporation, USA). The modified BORG scale $(0-10)^{37}$ was 
used to quantify the level of dyspnoea (BORGd) and leg fatigue (BORGf) prior to starting the test, each minute during the test, and on test completion.

Measures of oxygen uptake and minute ventilation collected over the final 20 seconds previous to their highest value were averaged to calculate $\mathrm{VO}_{2 \text { peak }}$ and maximum minute ventilation (VEmax). ${ }^{14,38,39}$ Measures of maximum work rate (Wmax) and $\mathrm{VO}_{2 \text { peak }}$ were expressed in absolute values and as a percentage of the predicted value. ${ }^{40} \mathrm{~A}$ single CPET was completed as studies in healthy people and in people with COPD have shown no improvement when a second test was performed. ${ }^{14}$

\section{$\underline{\text { Six-minute walk test }}$}

The 6MWT was undertaken according to the ERS/ATS recommendations, ${ }^{26}$ with encouragement to walk as far and as fast as possible. The test was performed over a 45$\mathrm{m}$ straight course within an enclosed corridor, which is consistent with the course used to develop the reference equations for the Australian population. ${ }^{41}$ Standardised encouragement was given at the end of every minute. Also, at the end of every minute, measures were collected of HR (Polar-a1; Polar Electro Oy, Finland) and $\mathrm{SpO}_{2}(\mathrm{Rad}-$ 57; Masimo Corporation, USA). The modified BORG scale ${ }^{37}$ was used to quantify level of dyspnoea and leg fatigue prior to starting the test and on test completion. 
Two tests, separated by a 30-minute rest period, were conducted and the best 6MWD was recorded as the test result. Further, the six-minute walk work (6MWW) was calculated as the product of 6MWD (expressed in $\mathrm{km}$ ) and weight (expressed in $\mathrm{kg}$ ). This variable represents the work of walking. ${ }^{42}$ For each participant, the $6 \mathrm{MWD}$ was expressed in absolute values and as a percentage of their predicted value. ${ }^{41}$

\section{Statistical analysis}

Statistical analyses were performed using $\operatorname{SPSS}^{\circledR}$ (Statistical Package for Social Sciences, version 22.0) and SigmaPlot (version 12.0). The distribution of data was examined using the Shapiro-Wilk test. Exercise capacity, peak $\mathrm{HR}$, nadir $\mathrm{SpO}_{2}$, end-test BORGd and BORGf elicited during the two tests were compared using paired $t$-tests. Differences between the exercise tests are expressed as mean difference (MD) [95\% confidence interval (CI)]. Clinically important oxygen desaturation during the 6MWT and CPET was defined as a $>4 \%$ fall in $\mathrm{SpO}_{2}$ from resting measures, to a value $<90 \%$. ${ }^{43}$ A subgroup analysis comparing exercise responses during the two tests in people diagnosed with COPD $^{44}$ versus people not diagnosed with COPD was undertaken using an independent $t$-test. In order to compare the patterns of changes in measures of HR and $\mathrm{SpO}_{2}$ during each test, data were grouped into deciles (i.e. epochs equivalent to $10 \%$ of the total test duration) using a two-dimensional data transformation. Comparison of 
both $\mathrm{HR}$ and $\mathrm{SpO}_{2}$ at each decile throughout the 6MWT and the CPET was performed using a one-way repeated measures analysis of variance with Tukey’s post-hoc.

Correlations between variables from the 6MWT (i.e. 6MWD and 6MWW) and variables from the CPET (i.e. $\mathrm{VO}_{2 \text { peak }}$ and Wmax) were calculated utilising Pearson's correlation coefficient (see online supplementary material). The effect of test repetition on 6MWD was examined using a paired $t$-test. For all analyses, a $p$ value $\leq 0.05$ was considered significant. Data are expressed as mean \pm standard deviation (SD).

This study represents a secondary analysis of data collected as part of a larger study that compared several outcomes in people following curative intent treatment for NSCLC with those in age and gender-matched healthy controls. ${ }^{45}$ For the larger study, ${ }^{45}$ the sample size calculation indicated that 18 participants with NSCLC and 18 healthy controls were needed to detect a between-group difference in $\mathrm{VO}_{2 \text { peak }}$ of $0.55 \mathrm{~L} \cdot \mathrm{min}^{-1}$ with a standard deviation of $0.57 \mathrm{~L} \cdot \mathrm{min}^{-1}(\alpha=0.05,1-\beta=0.8)$. Data collected in the participants with NSCLC who completed this larger study were used in the analyses presented in the current study. 


\section{Results}

Ninety-six people following lobectomy were screened to participate in this study, of whom $71 \%(n=68)$ were eligible and approached. Of these, $22(32 \%)$ consented to participate. The reasons for declining participation were; (i) difficulty with travelling to the hospital ( $\mathrm{n}=16)$, (ii) no free time to attend assessments $(\mathrm{n}=11)$, (iii) lack of interest ( $\mathrm{n}=11$ ), (iv) personal issues ( $\mathrm{n}=6$ ), and (v) travelling overseas for the next couple of weeks $(n=2)$. Two of the 22 were withdrawn due to health issues not related to lung cancer. Complete CPET and 6MWT data were available in 20 participants. The first assessment day ocurred $56 \pm 18$ days following lobectomy. One participant received chemotherapy and their first assessment day ocurred 28 days following their last cycle of chemotherapy. Characteristics of the participants are presented in Table 1 . Their median (interquartile range) MMRC grade was 1 (1 to 1.75$)$. Ten participants (50\%) had a diagnosis of COPD. Their characteristics are presented in the online supplementary material. 


\section{Cardiopulmonary exercise test}

Results of the CPET are shown in Table 2 and Table 3. One participant (5\%) desaturated $>4 \%$ to a $\mathrm{SpO}_{2}$ of $87 \%$ during the test. There was no difference between end-test BORGd (6.9 \pm 2.6$)$ and end-test BORGf $(6.8 \pm 2.4)(p=0.87)$. A total of four (20\%) participants demonstrated evidence of a ventilatory limitation to exercise, defined as a ratio of VEmax to maximum voluntary ventilation (VEmax/MVV) of $>85 \%{ }^{14}$ These participants had spirometric evidence of COPD.

\section{Six-minute walk test}

Results of the best 6MWT are shown in Table 2 and Table 3. Two participants (10\%) desaturated $>4 \%$ to a $\mathrm{SpO}_{2}<90 \%$ during the test. There was no difference between endtest BORGd (3.1 \pm 1.6$)$ and end-test BORGf $(2.0 \pm 1.9)(p=0.06)$.

\section{Comparison of exercise responses during the two exercise tests}

The impairment in exercise capacity expressed in terms of $\mathrm{VO}_{2 \text { peak }}$ was greater than the

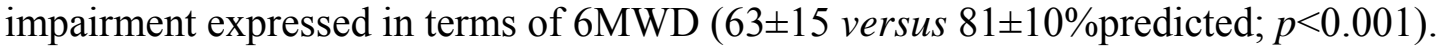
Table 3 presents a comparison of $\mathrm{HR}, \mathrm{SpO}_{2}$ and symptoms between the two tests. Compared with responses measured during the CPET, the 6MWT elicited a lower peak HR (MD [95\% CI]; -9[-16 to -1$] \mathrm{bpm} ; p=0.02$ ) and greater oxygen desaturation (MD 
$[95 \% \mathrm{CI}]$ nadir $\mathrm{SpO}_{2} ;-2[-4$ to -1$\left.] \% ; p=0.01\right)$. Both the BORGd and BORGf were also lower on completion of the 6MWT (MD [95\% CI]; $-4[-5$ to -3$]$ and $-5[-6$ to -3$]$, respectively; $p<0.001$ for both).

The pattern of change in $\mathrm{HR}$ and $\mathrm{SpO}_{2}$ during the two tests is presented in Figure 1. During the CPET, HR increased linearly with time whereas, during the 6MWT, HR increased from the beginning of the test until the end of the third minute $(\Delta \mathrm{HR}$; $32 \pm 12 \mathrm{bpm} ; p<0.001)$ after which, there was a plateau until test completion $(\Delta \mathrm{HR}$ between the end of the third minute and test completion; $4 \pm 4 \mathrm{bpm} ; p=0.34)$. During the CPET, there was a linear decrease in $\mathrm{SpO}_{2}$ whereas, during the 6MWT, there was a reduction in $\mathrm{SpO}_{2}$ from the beginning of the test until the end of the second minute $\left(\Delta \mathrm{SpO}_{2} ;-3 \pm 2 \% ; p=0.01\right)$ after which, there was a plateau until test completion $\left(\Delta \mathrm{SpO}_{2}\right.$ between the end of the second minute and test completion; $-1 \pm 1 \% ; p=0.67$ ).

\section{Effect of test repetition on 6MWD}

The 6MWD increased with test repetition from $484 \pm 72$ to $503 \pm 71 \mathrm{~m} ; p<0.001$. The mean difference was $19 \pm 19 \mathrm{~m}$ (range: -8 to $57 \mathrm{~m}$ ) or $4 \pm 4 \%$ (range: -2 to $20 \%$ ). Eighteen of the 20 participants $(90 \%)$ walked further on the second $6 \mathrm{MWT}$. None of the participants required a rest during the tests. 
Subgroup analyses comparing responses of people with COPD to people without COPD

No difference between those with and without COPD were found in any of the exercise responses during the two tests (see online supplementary material). 


\section{Discussion}

The important findings of this study are that in people following curative intent treatment for NSCLC; (i) the impairment in exercise capacity measured during the CPET, expressed as $\mathrm{VO}_{2 \text { peak }}(\%$ predicted) was considerably greater than the impairment expressed as 6MWD (\% predicted), (ii) the causes of exercise limitation were variable with a small proportion of participants demonstraing evidence of ventilatory limitation, (iii) compared with the CPET, the 6MWT elicited a lower peak HR, less symptoms of dyspnoea and leg fatigue, but greater oxygen desaturation, and (iv) the 6MWD increased with test repetition. Differences in the pattern of response in HR and $\mathrm{SpO}_{2}$ were observed during the CPET and 6MWT.

During the CPET, people following curative intent treatment for NSCLC achieved a $\mathrm{VO}_{2 \text { peak }}$ of $15 \pm 3 \mathrm{ml} \cdot \mathrm{kg}^{-1} \cdot \mathrm{min}^{-1}$ or $63 \pm 15 \%$ predicted. The impairment in $6 \mathrm{MWD}$ was less, being $503 \pm 71 \mathrm{~m}$ or $81 \pm 10 \%$ predicted. Therefore, it seems that people following curative intent treatment for NSCLC have considerable impairment in peak exercise capacity, but relatively modest impairment in the capacity to walk as far as possible in 6 minutes. Regarding the mechanisms of exercise limitation, four (20\%) participants, all of whom had evidence of COPD, demonstrated evidence of a ventilatory limitation. Although the other six participants with spirometric evidence of COPD did not demonstrate a ventilatory limitation, we cannot be certain that they did not develop lung 
hyperinflation during exercise as we did not perform flow-volume loops or monitor changes in inspiratory capacity. Earlier work has shown that people with mild COPD progressively develop lung hyperinflation during exercise and this contributes to their sensation of dyspnoea. ${ }^{46}$ In those without COPD, the most likely mechanism of limitation was peripheral muscle deconditioning.

Our data show that compared with the CPET, the 6MWT elicited a lower peak HR and less symptoms. This is different to earlier work in people with COPD, which shows that the CPET and 6MWT elicit a similar peak HR as their ventilatory limitation to exercise precludes them from attaining a higher peak HR during the CPET. ${ }^{18,19}$ The implications these findings are three-fold. First, for clinicians who are unable to access CPET, people following curative intent treatment for NSCLC who present with modest impairments in 6MWD may have considerable impairment in peak exercise capacity, and therefore may still benefit from participating in exercise training. Second, given that the mean 6MWD was greater than $500 \mathrm{~m}$, or $80 \%$ predicted, it is possible that this test is not as responsive as it is in people with moderate-to-severe COPD to change following exercise training. ${ }^{47}$ Although earlier work in people with bronchiectasis, who were characterised by a high baseline 6MWD, demonstrated an increase in 6MWD of 41m (95\%CI 19 to $63 \mathrm{~m}$ ) following 8 weeks of exercise training, ${ }^{48}$ alternative field-based tests, such as the modified incremental shuttle walk test ${ }^{49}$ may be more responsive to change following interventions. Third, the way in which the 6MWD has been used to prescribe the 
intensity of walking-based training in people with COPD may require some reconsideration in people following curative intent treatment for NSCLC. That is, in people with COPD, although the 6MWT has been shown to elicit similar peak responses as the CPET, walking-based exercise training is often prescribed at a high percentage (e.g. $80 \%$ ) of the average speed achieved during the $6 \mathrm{MWT} .{ }^{24}$ In contrast, our data shows that in people following curative intent treatment for NSCLC, the 6MWT elicited sub-maximal responses. As the 6MWT is a sub-maximal test in this population, it is likely that they will tolerate an initial prescription of walking-based training at any intensity greater than that used for COPD. ${ }^{25}$

The magnitude of impairment in $\mathrm{VO}_{2 \text { peak }}$ and 6MWD between those with and without COPD was very similar. Although the lack of statistical difference is likely to reflect the small sample size available for this comparison, the data suggest that any difference is very small and unlikely to be clinically meaningful. The similarity in measures between those with versus without COPD may also relate to the fact that our sample included individuals with mild-to-moderate, rather than severe airflow obstruction.

Although the extent of oxygen desaturation observed during both tests was modest, the $\mathrm{SpO}_{2}$ of people following curative intent treatment for NSCLC decreased to a greater extent during the 6MWT. Greater desaturation during walking compared with cycle based exercise corroborates the findings of previous studies in people with moderate-to- 
severe COPD. ${ }^{18-21,50}$ Had the CPET been performed on a treadmill, it is unlikely that the decrease in $\mathrm{SpO}_{2}$ would have been different between the two tests. ${ }^{51}$ The finding of greater oxygen desaturation during the 6MWT in this study may relate to both the larger muscle mass involved in walking compared to cycling and the specific load imposed on the quadriceps during cycle based exercise, which results in a significant concentration of blood lactate on test completion, heightening the ventilatory response. ${ }^{52}$ The specific load on the quadriceps is likely to explain the greater severity of symptoms seen during the CPET and the higher level of ventilation previously reported during cycle based exercise serves to minimise the extent of desaturation. ${ }^{51,53}$

This study revealed clear differences in patterns of $\mathrm{HR}$ and $\mathrm{SpO}_{2}$ responses during the 6MWT compared to the CPET. Whilst HR and $\mathrm{SpO}_{2}$ during the CPET changed gradually and linearly with time, during the 6MWT these two variables changed exponentially over the first 2 to 3 minutes of the test, followed by a relative plateau until test completion. These patterns of response are consistent with data reported in people with moderate-to-severe COPD, ${ }^{18,19}$ and reflect the way in which these tests are conducted. That is, compared to the CPET in which work rate increases in a linear fashion, work rate during the 6MWT is almost constant after the initial acceleration. ${ }^{19,54}$ Consistent with earlier work in COPD, both Wmax and $\mathrm{VO}_{2 \text { peak }}$ were associated with 6MWD. The strength of this association increased when work done during the 6MWT was considered by using the variable $6 \mathrm{MWW}^{42,55}$ 
Our data demonstrated that there was a significant effect of test repetition. The 6MWD improved by an average of $19 \mathrm{~m}$ ( or $4 \%$ ) on the second test. This is consistent with findings from studies in people with COPD (mean increase ranges from 13 to $37 \mathrm{~m}$ or 4 to $11 \%)^{22,56,57}$ and idiopathic pulmonary fibrosis (mean increase reported to be $11 \mathrm{~m}$ or $4 \%){ }^{22}$ This finding supports that a minimum of two 6MWT should be used when assessing people following curative intent treatment for NSCLC.

\section{Limitations}

Although our sample size was somewhat modest, it was similar to that of previous studies that have compared responses during the CPET to those during field-based walk tests in people with COPD (sample size ranged from 20 to 24 participants) ${ }^{18-20}$ and greater than a previous study in people with heart failure $(n=15) .{ }^{58}$ We acknowledge that the sample may not be large enough to detect differences between the subgroup of people with COPD and the subgroup of people who did not have COPD. We also acknowledge that the use of reference equations to quantify impairment in exercise capacity has its limitations. That is, differences in sample characteristics, equipment and assessment protocols between the study that developed the regression equations and the current study may have introduced error to our estimate of impairment, expressed as a percentage of the predicted value in a healthy population. As measures of exercise capacity were not collected prior to and following a specific intervention, we were not 
able to investigate the responsiveness of the two tests. The need for a third 6MWT was not assessed, however data from previous study in people with COPD demonstrated no significant increase in distance on a third test. ${ }^{20}$ Another limitation is that ventilatory and metabolic responses during the $6 \mathrm{MWT}$ were not measured using a portable gas analysis system. Additionally, people who underwent wedge resection or pneumonectomy for NSCLC were not included in the study, thus the results cannot be extended to all people undergoing lung resection for NSCLC.

In conclusion, this study demonstrated that people following curative intent treatment for NSCLC presented with greater impairment in exercise capacity expressed as $\mathrm{VO}_{\text {2peak }}$ than as $6 \mathrm{MWD}$. This suggests that those who present with modest impairments in 6MWD may have considerable impairment in peak exercise capacity, and may still benefit from participating in exercise training. The $\mathrm{SpO}_{2}$ of people following curative intent treatment for NSCLC decreased to a greater extent during the 6MWT, and therefore this test may assist in identifying those who desaturate during exercise. In contrast to people with COPD, in whom the 6MWT and CPET elicit similar peak $\mathrm{VO}_{2 \text { peak }}$ and $\mathrm{HR}$ response, in people following curative intent treatment for NSCLC, the 6MWT elicited sub-maximal responses. As the 6MWT is a sub-maximal test in this population, it is likely that they will tolerate an initial prescription of walking-based training at an intensity greater than that used for COPD, which is often $80 \%$ of the average walking speed achieved during the 6MWT. A minimum of two 6MWTs need to 
be performed as the 6MWD increased with test repetition. Future studies should investigate; (i) the optimal initial speed for the walking training prescription based on the average walking speed achieved during the $6 \mathrm{MWT}$, (ii) the responsiveness of the 6MWT to interventions such as exercise training, and (iii) properties of other common field-based walking tests such as the incremental and endurance shuttle walk test in people following curative intent treatment for NSCLC. 


\section{Acknowledgements}

VC is supported by the Curtin Strategic International Research Scholarship (CSIRS) and Lung Institute of Western Australia (LIWA) PhD Top-up Scholarship.

\section{Conflict of interest}

The authors declare no conflict of interest.

\section{Funding}

The study received funding from Sir Charles Gairdner Hospital Research Advisory Committee (grant number: 2011/12/013). 


\section{References}

1. Alberg AJ, Brock MV, Ford JG, Samet JM and Spivack SD. Epidemiology of lung cancer: Diagnosis and management of lung cancer, 3rd ed: American College of Chest Physicians evidence-based clinical practice guidelines. Chest. 2013; 143: e1S29S.

2. Howington JA, Blum MG, Chang AC, Balekian AA and Murthy SC. Treatment of stage I and II non-small cell lung cancer: Diagnosis and management of lung cancer, 3rd ed: American College of Chest Physicians evidence-based clinical practice guidelines. Chest. 2013; 143: e278S-313S.

3. AIHW and Cancer Australia 2011. Lung cancer in Australia an overview. Cat. no. CAN 58. Canberra AIHW.

4. Jones LW. Physical activity and lung cancer survivorship. Recent Results Cancer Res. 2011; 186: 255-74.

5. Pelletier C, Lapointe L and LeBlanc P. Effects of lung resection on pulmonary function and exercise capacity. Thorax. 1990; 45: 497-502.

6. Nagamatsu Y, Maeshiro K, Kimura NY, et al. Long-term recovery of exercise capacity and pulmonary function after lobectomy. J Thorac Cardiovasc Surg. 2007; 134: $1273-8$. 
7. Win T, Groves AM, Ritchie AJ, Wells FC, Cafferty F and Laroche CM. The effect of lung resection on pulmonary function and exercise capacity in lung cancer patients. Respir Care. 2007; 52: 720-6.

8. Wang JS, Abboud RT and Wang LM. Effect of lung resection on exercise capacity and on carbon monoxide diffusing capacity during exercise. Chest. 2006; 129: 863-72.

9. Nezu K, Kushibe K, Tojo T, Takahama M and Kitamura S. Recovery and limitation of exercise capacity after lung resection for lung cancer. Chest. 1998; 113: 1511-6.

10. Bolliger CT, Jordan P, Soler M, et al. Pulmonary function and exercise capacity after lung resection. Eur Respir J. 1996; 9: 415-21.

11. Edvardsen E, Skjonsberg OH, Holme I, Nordsletten L, Borchsenius F and Anderssen SA. High-intensity training following lung cancer surgery: a randomised controlled trial. Thorax. 2014.

12. Cavalheri V, Tahirah F, Nonoyama M, Jenkins S and Hill K. Exercise training for people following lung resection for non-small cell lung cancer - A Cochrane systematic review. Cancer Treat Rev. 2014; 40: 585-94.

13. Cavalheri V, Tahirah F, Nonoyama M, Jenkins S and Hill K. Exercise training undertaken by people within 12 months of lung resection for non-small cell lung cancer. Cochrane Database Syst Rev. 2013; 7: CD009955. 
14. ATS/ACCP Statement on cardiopulmonary exercise testing. Am J Respir Crit Care Med. 2003; 167: 211-77.

15. Johnston CL, Maxwell LJ and Alison JA. Pulmonary rehabilitation in Australia: a national survey. Physiotherapy. 2011.

16. Spruit MA, Pitta F, Garvey C, et al. Differences in content and organisational aspects of pulmonary rehabilitation programmes. Eur Respir J. 2014; 43: 1326-37.

17. Desveaux L, Janaudis-Ferreira T, Goldstein R and Brooks D. An international comparison of pulmonary rehabilitation: a systematic review. COPD. 2015; 12: 144-53.

18. Hill K, Dolmage TE, Woon L, Coutts D, Goldstein R and Brooks D. Comparing peak and submaximal cardiorespiratory responses during field walking tests with incremental cycle ergometry in COPD. Respirology. 2012; 17: 278-84.

19. Troosters T, Vilaro J, Rabinovich R, et al. Physiological responses to the 6-min walk test in patients with chronic obstructive pulmonary disease. Eur Respir J. 2002; 20: 564-9.

20. Turner SE, Eastwood PR, Cecins NM, Hillman DR and Jenkins SC. Physiologic responses to incremental and self-paced exercise in COPD: a comparison of three tests. Chest. 2004; 126: 766-73.

21. Luxton N, Alison JA, Wu J and Mackey MG. Relationship between field walking tests and incremental cycle ergometry in COPD. Respirology. 2008; 13: 85662. 
22. Kozu R, Jenkins S, Senjyu H, Mukae H, Sakamoto N and Kohno S. Peak power estimated from 6-minute walk distance in Asian patients with idiopathic pulmonary fibrosis and chronic obstructive pulmonary disease. Respirology. 2010; 15: 706-13.

23. Fowler RM, Jenkins SC, Maiorana AJ, Gain KR, O'Driscoll G and Gabbay E. Measurement properties of the 6-min walk test in individuals with exercise-induced pulmonary arterial hypertension. Intern Med J. 2011; 41: 679-87.

24. Jenkins S, Hill K and Cecins NM. State of the art: how to set up a pulmonary rehabilitation program. Respirology. 2010; 15: 1157-73.

25. Zainuldin R, Mackey MG and Alison JA. Prescription of walking exercise intensity from the 6-minute walk test in people with chronic obstructive pulmonary disease. J Cardiopulm Rehabil Prev. 2015; 35: 65-9.

26. Holland AE, Spruit MA, Troosters T, et al. An official European Respiratory Society/American Thoracic Society technical standard: field walking tests in chronic respiratory disease. Eur Respir J. 2014; 44: 1428-46.

27. Singh SJ, Puhan MA, Andrianopoulos V, et al. An official systematic review of the European Respiratory Society/American Thoracic Society: measurement properties of field walking tests in chronic respiratory disease. Eur Respir J. 2014; 44: 1447-78.

28. Fletcher CM, Elmes PC, Fairbairn AS and Wood CH. The significance of respiratory symptoms and the diagnosis of chronic bronchitis in a working population. Br Med J. 1959; 2: 257-66. 
29. Celli BR, Cote CG, Marin JM, et al. The body-mass index, airflow obstruction, dyspnea, and exercise capacity index in chronic obstructive pulmonary disease. $N$ Engl J Med. 2004; 350: 1005-12.

30. Miller MR, Hankinson J, Brusasco V, et al. Standardisation of spirometry. Eur Respir J. 2005; 26: 319-38.

31. Macintyre N, Crapo RO, Viegi G, et al. Standardisation of the single-breath determination of carbon monoxide uptake in the lung. Eur Respir J. 2005; 26: 720-35.

32. American Thoracic Society/European Respiratory S. ATS/ERS Statement on respiratory muscle testing. Am J Respir Crit Care Med. 2002; 166: 518-624.

33. Hankinson JL, Odencrantz JR and Fedan KB. Spirometric reference values from a sample of the general U.S. population. Am J Respir Crit Care Med. 1999; 159: 17987.

34. Crapo RO and Morris AH. Standardized single breath normal values for carbon monoxide diffusing capacity. Am Rev Respir Dis. 1981; 123: 185-9.

35. Pretto JJ, Braun GW and Guy PA. Using baseline respiratory function data to optimize cycle exercise test duration. Respirology. 2001; 6: 287-91.

36. Buchfuhrer MJ, Hansen JE, Robinson TE, Sue DY, Wasserman K and Whipp BJ. Optimizing the exercise protocol for cardiopulmonary assessment. Journal of applied physiology: respiratory, environmental and exercise physiology. 1983; 55: 1558-64. 
37. Borg GA. Psychophysical bases of perceived exertion. Med Sci Sports Exerc. 1982; $14: 377-81$.

38. Nanas S, Sakellariou D, Kapsimalakou S, et al. Heart rate recovery and oxygen kinetics after exercise in obstructive sleep apnea syndrome. Clin Cardiol. 2010; 33: 4651.

39. Win T, Jackson A, Groves AM, Sharples LD, Charman SC and Laroche CM. Comparison of shuttle walk with measured peak oxygen consumption in patients with operable lung cancer. Thorax. 2006; 61: 57-60.

40. Blackie SP, Fairbarn MS, McElvaney GN, Morrison NJ, Wilcox PG and Pardy RL. Prediction of maximal oxygen uptake and power during cycle ergometry in subjects older than 55 years of age. Am Rev Respir Dis. 1989; 139: 1424-9.

41. Jenkins S, Cecins N, Camarri B, Williams C, Thompson P and Eastwood P. Regression equations to predict 6-minute walk distance in middle-aged and elderly adults. Physiother Theory Pract. 2009; 25: 516-22.

42. Chuang ML, Lin IF and Wasserman K. The body weight-walking distance product as related to lung function, anaerobic threshold and peak VO2 in COPD patients. Respir Med. 2001; 95: 618-26.

43. Clinical component for the home oxygen service in England and Wales. British Thoracic Society, 2006. 
44. Global Strategy for the Diagnosis, Management and Prevention of COPD, Global Initiative for Chronic Obstructive Lung Disease (GOLD) 2015. Available from: http://www.goldcopd.org/.

45. Cavalheri V, Jenkins $\mathrm{S}$, Cecins $\mathrm{N}$, et al. Impairments after curative intent treatment for non-small cell lung cancer: A comparison with age and gender-matched healthy controls. Respir Med. 2015.

46. Ofir D, Laveneziana P, Webb KA, Lam YM and O'Donnell DE. Mechanisms of dyspnea during cycle exercise in symptomatic patients with GOLD stage I chronic obstructive pulmonary disease. Am J Respir Crit Care Med. 2008; 177: 622-9.

47. Frost AE, Langleben D, Oudiz R, et al. The 6-min walk test (6MW) as an efficacy endpoint in pulmonary arterial hypertension clinical trials: demonstration of a ceiling effect. Vascular pharmacology. 2005; 43: 36-9.

48. Lee AL, Hill CJ, Cecins N, et al. Minimal important difference in field walking tests in non-cystic fibrosis bronchiectasis following exercise training. Respir Med. 2014; 108: $1303-9$.

49. Campo LA, Chilingaryan G, Berg K, Paradis B and Mazer B. Validity and reliability of the modified shuttle walk test in patients with chronic obstructive pulmonary disease. Arch Phys Med Rehabil. 2006; 87: 918-22. 
50. Poulain M, Durand F, Palomba B, et al. 6-minute walk testing is more sensitive than maximal incremental cycle testing for detecting oxygen desaturation in patients with COPD. Chest. 2003; 123: 1401-7.

51. Hsia D, Casaburi R, Pradhan A, Torres E and Porszasz J. Physiological responses to linear treadmill and cycle ergometer exercise in COPD. Eur Respir J. 2009; 34: 605-15.

52. Man WD, Soliman MG, Gearing J, et al. Symptoms and quadriceps fatigability after walking and cycling in chronic obstructive pulmonary disease. Am J Respir Crit Care Med. 2003; 168: 562-7.

53. Mahler DA, Gifford AH, Waterman LA, Ward J, Machala S and Baird JC. Mechanism of greater oxygen desaturation during walking compared with cycling in patients with COPD. Chest. 2011; 140: 351-8.

54. Butland RJ, Pang J, Gross ER, Woodcock AA and Geddes DM. Two-, six-, and 12-minute walking tests in respiratory disease. British medical journal. 1982; 284: $1607-8$.

55. Carter R, Holiday DB, Nwasuruba C, Stocks J, Grothues C and Tiep B. 6minute walk work for assessment of functional capacity in patients with COPD. Chest. 2003; 123: 1408-15. 
56. Hernandes NA, Wouters EF, Meijer K, Annegarn J, Pitta F and Spruit MA. Reproducibility of 6-minute walking test in patients with COPD. Eur Respir J. 2011; 38: $261-7$.

57. Jenkins $\mathrm{S}$ and Cecins NM. Six-minute walk test in pulmonary rehabilitation: do all patients need a practice test? Respirology. 2010; 15: 1192-6.

58. Deboeck G, Muylem AV, Vachiery JL and Naeije R. Physiological response to the 6-minute walk test in chronic heart failure patients versus healthy control subjects. Eur J Prev Cardiol. 2013. 


\section{Legend of Figure}

Figure 1: Patterns of responses for: A) heart rate (HR) and B) peripheral capillary oxygen saturation $\left(\mathrm{SpO}_{2}\right)$ for each test. Data are mean and standard error. All participants contributed to each decile (data point). $\bullet$, cardiopulmonary exercise test (CPET); $\mathbf{n}$, six-minute walk test. For the CPET, time 0 (zero) is the start of the ramp. *Plateau from this data point to test completion. 
Figure 1

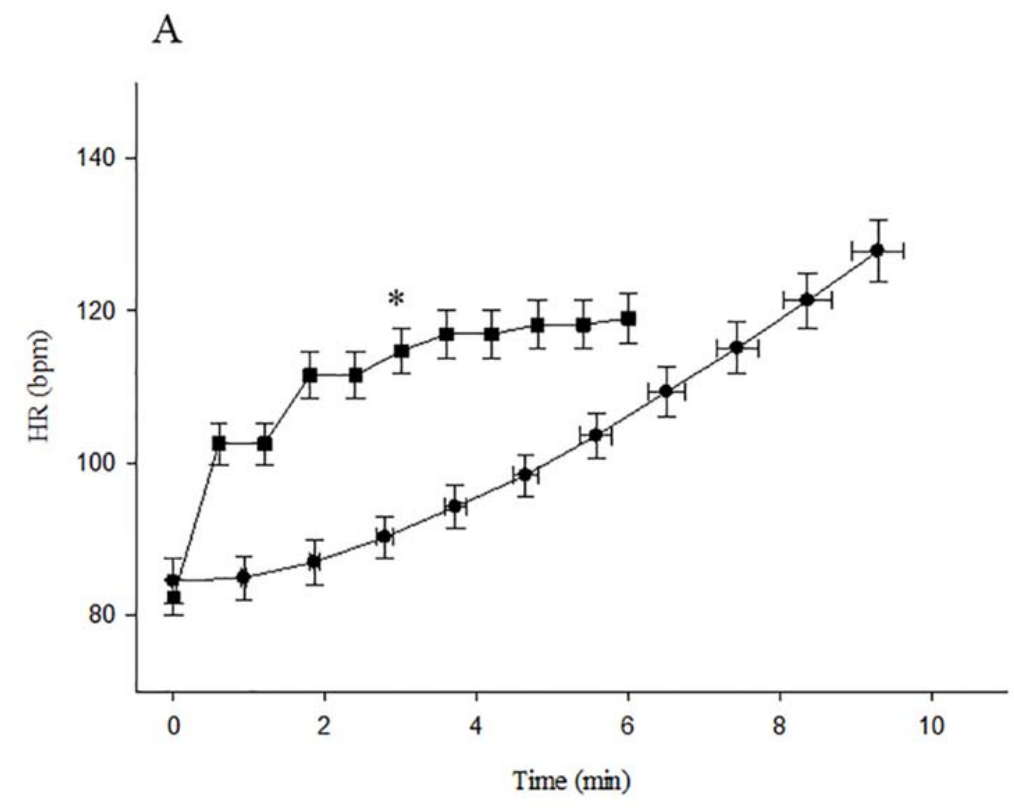

B

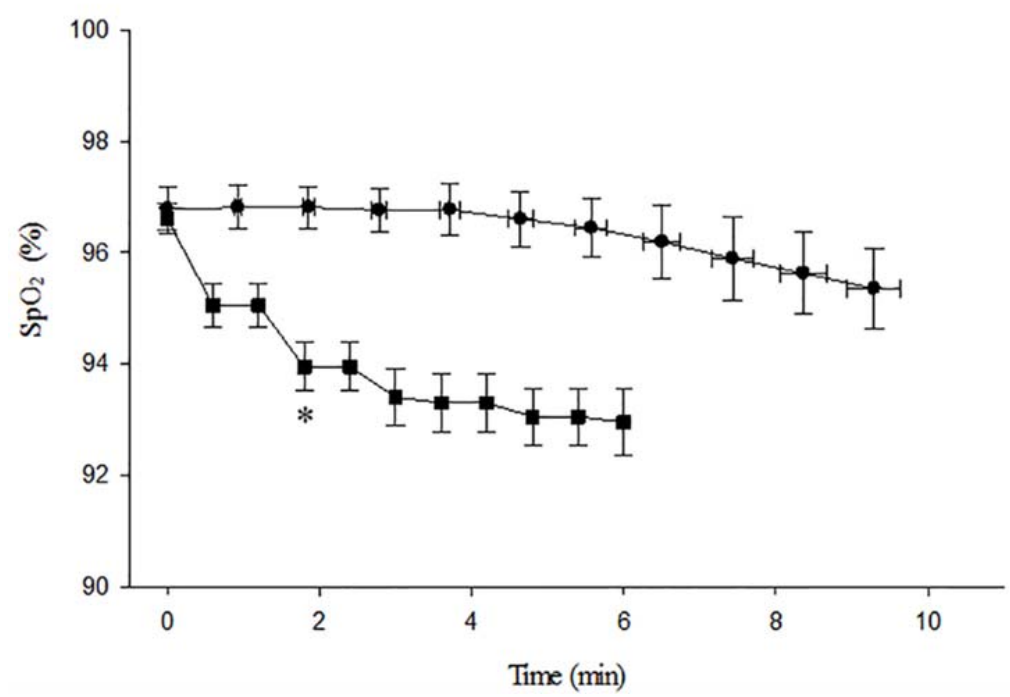


Table 1: Participant characteristics $(n=20)$

\begin{tabular}{|c|c|c|}
\hline Variable & \multicolumn{2}{|c|}{ Mean \pm SD } \\
\hline Age (yr) & \multicolumn{2}{|c|}{$67 \pm 10$} \\
\hline $\mathrm{BMI}\left(\mathrm{kg} \cdot \mathrm{m}^{-2}\right)$ & \multicolumn{2}{|c|}{$26 \pm 6$} \\
\hline Smoking (pack/yr) & \multicolumn{2}{|c|}{$36 \pm 26$} \\
\hline $\mathrm{FEV}_{1}(\mathrm{~L})$ & \multicolumn{2}{|c|}{$1.65 \pm 0.49$} \\
\hline $\mathrm{FEV}_{1}$ (\%pred) & \multicolumn{2}{|c|}{$67 \pm 16$} \\
\hline $\mathrm{FVC}(\mathrm{L})$ & \multicolumn{2}{|c|}{$2.69 \pm 0.72$} \\
\hline FVC (\%pred) & \multicolumn{2}{|c|}{$81 \pm 11$} \\
\hline $\mathrm{FEV}_{1} / \mathrm{FVC}$ & \multicolumn{2}{|c|}{$0.63 \pm 0.12$} \\
\hline $\mathrm{D}_{\mathrm{L}} \mathrm{CO}\left(\mathrm{ml} \cdot \mathrm{mmHg}^{-1} \cdot \mathrm{min}^{-1}\right)$ & \multirow{2}{*}{\multicolumn{2}{|c|}{$\begin{array}{c}13.6 \pm 3.4 \\
53 \pm 11\end{array}$}} \\
\hline \multirow{2}{*}{$\mathrm{D}_{\mathrm{L}} \mathrm{CO}$ (\%pred) } & & \\
\hline & $\mathbf{n}$ & $\%$ \\
\hline Gender, male/female & $6 / 14$ & $30 / 70$ \\
\hline \multicolumn{3}{|l|}{ Smoking status } \\
\hline Ex-smoker & 17 & 85 \\
\hline Never smoked & 3 & 15 \\
\hline \multicolumn{3}{|l|}{ Type of NSCLC } \\
\hline Adenocarcinoma & 13 & 65 \\
\hline Squamous cell carcinoma & 6 & 30 \\
\hline Large cell carcinoma & 1 & 5 \\
\hline \multicolumn{3}{|l|}{ NSCLC stage } \\
\hline I & 16 & 80 \\
\hline II & 3 & 15 \\
\hline IIIA & 1 & 5 \\
\hline \multicolumn{3}{|l|}{ Type of surgery (lobectomy) } \\
\hline Open & 9 & 45 \\
\hline VATS & 11 & 55 \\
\hline Adjuvant chemotherapy & 1 & 5 \\
\hline
\end{tabular}

Abbreviations: BMI - Body-mass index; $\mathrm{D}_{\mathrm{L}} \mathrm{CO}$ - Single breath diffusing capacity for carbon monoxide; $\mathrm{FEV}_{1}$ - Forced expiratory volume in one second; FVC - Forced vital capacity; NSCLC Non-small cell lung cancer; SD - Standard deviation; VATS - Video-assisted thoracoscopic surgery. 
Table 2: Results of the exercise tests

\begin{tabular}{|c|c|}
\hline Variable $(n=20)$ & Mean \pm SD \\
\hline \multicolumn{2}{|l|}{ CPET } \\
\hline Duration (min) & $9.3 \pm 1.6$ \\
\hline $\mathrm{VO}_{\text {2peak }}\left(\mathrm{L} \cdot \mathrm{min}^{-1}\right)$ & $1.03 \pm 0.31$ \\
\hline $\mathrm{VO}_{2 \text { peak }}\left(\mathrm{ml} \cdot \mathrm{kg}^{-1} \cdot \mathrm{min}^{-1}\right)$ & $15 \pm 3$ \\
\hline $\mathrm{VO}_{2 \text { peak }}(\%$ pred $)$ & $63 \pm 15$ \\
\hline$W \max (W)$ & $76 \pm 26$ \\
\hline Wmax (\%pred) & $72 \pm 20$ \\
\hline$V \operatorname{Emax}\left(L \cdot \min ^{-1}\right)$ & $43 \pm 15$ \\
\hline VEmax/MVV $(\%)$ & $70 \pm 20$ \\
\hline $\mathrm{AT}\left(\% \mathrm{VO}_{2 \text { peak }}\right)$ & $61 \pm 10$ \\
\hline $\mathrm{O}_{2}$ pulse $\left(\mathrm{ml} \cdot\right.$ beat $\left.^{-1}\right)$ & $8 \pm 3$ \\
\hline fR (breaths $\cdot \mathrm{min}^{-1}$ ) & $36 \pm 4$ \\
\hline \multicolumn{2}{|l|}{ 6MWT } \\
\hline GMDD (m) & $503 \pm 71$ \\
\hline 6MWD (\%pred) & $81 \pm 10$ \\
\hline 6MWW (km·kg) & $35 \pm 11$ \\
\hline
\end{tabular}

Abbreviations: 6MWD - Six-minute walk distance; AT - Anaerobic threshold as a percentage of the $\mathrm{VO}_{2 \text { peak }}$; $6 \mathrm{MWT}$ - Six-minute walk test; 6MWW - Six-minute walk work; CPET - Cardiopulmonary exercise test; $\mathrm{f}$ R: Respiratory frequency; MVV Maximum voluntary ventilation; $\mathrm{O}_{2}$ pulse - Oxygen pulse; VEmax - Maximum minute ventilation; $\mathrm{VO}_{2 \text { peak }}$ - Peak rate of oxygen consumption; Wmax - Maximum work rate. 
Table 3: Comparison of $\mathrm{HR}, \mathrm{SpO}_{2}$ and symptoms during the 6MWT and CPET

\begin{tabular}{|c|c|c|}
\hline Variable $(n=20)$ & $\begin{array}{c}\text { CPET } \\
\text { mean } \pm \mathrm{SD}\end{array}$ & $\begin{array}{c}\text { 6MWT } \\
\text { mean } \pm \mathrm{SD}\end{array}$ \\
\hline Resting HR (bpm) & $85 \pm 13$ & $83 \pm 10$ \\
\hline Peak HR (bpm) & $128 \pm 18$ & $119 \pm 15^{*}$ \\
\hline Peak HR (\%pred HRmax) & $84 \pm 11$ & $79 \pm 10^{*}$ \\
\hline$\Delta \mathrm{HR}(\mathrm{bpm})$ & $44 \pm 16$ & $37 \pm 14$ \\
\hline Resting $\mathrm{SpO}_{2}(\%)$ & $97 \pm 2$ & $97 \pm 1$ \\
\hline Nadir $\mathrm{SpO}_{2}(\%)$ & $95 \pm 3$ & $93 \pm 2 *$ \\
\hline$\Delta \mathrm{SpO}_{2}(\%)$ & $-1 \pm 3$ & $-4 \pm 2 *$ \\
\hline End-test BORGd & $6.9 \pm 2.6$ & $3.1 \pm 1.6^{* *}$ \\
\hline End-test BORGf & $6.8 \pm 2.4$ & $2.0 \pm 1.9 * *$ \\
\hline
\end{tabular}

Abbreviations: 6MWT - Six-minute walk test; CPET - Cardiopulmonary exercise test; BORGd Dyspnoea; BORGf - Leg fatigue; $\mathrm{HR}$ - Heart rate; $\mathrm{SpO}_{2}$ - Peripheral capillary oxygen saturation measured via pulse oximetry; $\Delta \mathrm{SpO}_{2}-\left(\right.$ Nadir $\mathrm{SpO}_{2}-$ initial $\left.\mathrm{SpO}_{2}\right)$.

Statistically significant differences between tests: ${ }^{*} p<0.05 ;{ }^{* *} p<0.01$

"Maximum HR (HRmax) was calculated from the equation 220 - age. 


\section{Comparison of the six-minute walk test with a cycle-based cardiopulmonary exercise test in people following curative intent treatment for non-small cell lung cancer}

\section{Online supplementary material}

Table A1: Characteristics of participants with COPD versus without COPD

\begin{tabular}{|c|c|c|c|}
\hline Variable & $\begin{array}{c}\text { COPD }(\mathbf{n}=\mathbf{1 0}) \\
\text { mean } \pm S D\end{array}$ & $\begin{array}{c}\text { Non-COPD }(\mathbf{n}=\mathbf{1 0}) \\
\text { mean } \pm S D\end{array}$ & p value \\
\hline Age (yr) & $69 \pm 9$ & $65 \pm 11$ & 0.10 \\
\hline BMI $\left(\mathrm{kg} \cdot \mathrm{m}^{-2}\right)$ & $24 \pm 4$ & $28 \pm 6$ & 0.02 \\
\hline Smoking (pack·yr) & $42 \pm 22$ & $25 \pm 18$ & 0.001 \\
\hline $\mathrm{FEV}_{1}(\mathrm{~L})$ & $1.63 \pm 0.52$ & $1.67 \pm 0.48$ & 0.18 \\
\hline $\mathrm{FEV}_{1}$ (\%pred) & $62 \pm 16$ & $71 \pm 16$ & 0.06 \\
\hline FVC (L) & $2.93 \pm 0.76$ & $2.44 \pm 0.63$ & 0.02 \\
\hline FVC (\%pred) & $83 \pm 11$ & $78 \pm 10$ & 0.11 \\
\hline $\mathrm{FEV}_{1} / \mathrm{FVC}(\%)$ & $56 \pm 11$ & $71 \pm 8$ & 0.002 \\
\hline $\mathrm{D}_{\mathrm{L}} \mathrm{CO}\left(\mathrm{ml} \cdot \mathrm{mmHg}^{-1} \cdot \mathrm{min}^{-1}\right)$ & $13 \pm 4$ & $14 \pm 3$ & 0.42 \\
\hline DLCO (\%pred) & $48 \pm 10$ & $58 \pm 10$ & 0.02 \\
\hline
\end{tabular}

Abbreviations: BMI - Body-mass index; COPD - Chronic obstructive pulmonary disease; $\mathrm{D}_{\mathrm{L}} \mathrm{CO}$ - Single breath diffusing capacity for carbon monoxide; $\mathrm{FEV}_{1}$ - Forced expiratory volume in one second; FVC Force vital capacity. 


\section{Results}

\section{Cardiopulmonary exercise test}

There was no association between BORGd and BORGf reported on test completion $(\mathrm{r}=0.08 ; p=0.72)$.

\section{Six-minute walk test}

There was no association between BORGd and BORGf reported on test completion $(\mathrm{r}=0.42 ; p=0.07)$.

\section{Subgroup of people with COPD}

No differences were found in 6MWD or $\mathrm{VO}_{2 \text { peak }}$ between the subgroup of people with COPD and the subgroup of people not diagnosed with COPD (6MWD=501 \pm 92 [COPD] versus $506 \pm 47 \mathrm{~m}$ [non-COPD]; $\mathrm{VO}_{2 \mathrm{peak}}=15 \pm 3$ [COPD] versus $15 \pm 3 \mathrm{ml} \cdot \mathrm{kg}^{-1} \cdot \mathrm{min}^{-1}$ [nonCOPD]; $p>0.05$ for both). 